\title{
S100A8 Induces Secretion of MCP-1, IL-6, and IL-8 via TLR4 in Jurkat T Cells
}

\author{
A Reum Nam, Da Hae Kim², Mun Jeong Kim², Ji-Sook Lee ${ }^{3}$, \\ Seung-Ju Yang ${ }^{1, \dagger}$ and In Sik Kim ${ }^{2,4, \dagger}$ \\ ${ }^{I}$ Department of Biomedical Laboratory Science, Konyang University, Daejeon 35365, Korea \\ ${ }^{2}$ Department of Senior Healthcare, BK21 Plus Program, Graduate School, Eulji University, Daejeon 34824, Korea \\ ${ }^{3}$ Department of Clinical Laboratory Science, Wonkwang Health Science University, Iksan 54538, Korea \\ ${ }^{4}$ Department of Biomedical Laboratory Science, School of Medicine, Eulji University, Daejeon 34824, Korea
}

In the pathogenesis of inflammatory diseases such as allergies, S100A8 acts as an important molecule and $\mathrm{T}$ lymphocytes are essential cytokine-releasing cells. In this study, we investigated the effect of S100A8 on release of cytokines, specifically MCP-1, IL-6, and IL-8 in T cells, and its associated signaling mechanism. S100A8 increased secretion of MCP-1, IL-6, and IL-8 in a time- and dose-dependent manner. Elevated secretion of MCP-1, IL-6, and IL-8 due to S100A8 was inhibited by the TLR4 inhibitor TLR4i, the PI3K inhibitor LY294002, the PKC $\delta$ inhibitor rottlerin, the ERK inhibitor PD98059, the p38 MAPK inhibitor SB202190, the JNK inhibitor SP600125, and the NF-KB inhibitor BAY-11-7085. S100A8 induced phosphorylation of ERK, p38 MAPK, and JNK in a time-dependent manner, and

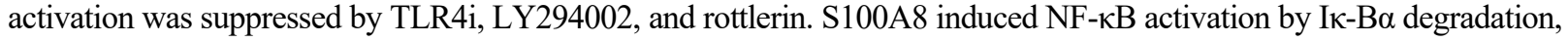
and NF- $\mathrm{KB}$ activity was suppressed by PD98059, SB202190, and SP600125. These results indicate that S100A8 induces cytokine release via TLR4. Study of PI3K, PKC $\delta$, MAPKs, and NF-kB will contribute to elucidation of the S100A8invovled mechanism.

Key Words: S100A8, Lymphocytes, Cytokine, TLR4

\section{INTRODUCTION}

S100A8, a calcium-binding protein, is included in the S100 protein family and induces a variety of physiological and pathological responses (Donato et al., 2013; Kim et al., 2013). S100A8 is important in embryo development and is associated with myeloid differentiation. S100A8 also inhibits production of reactive oxygen species (ROS) and stabilizes generation of nitric oxide. Dysregulation of S100A8 is an essential step in the outbreak and aggravation of allergic diseases, autoimmune diseases, and malignant tumors (Jin et al., 2014; Kang et al., 2015; Zheng et al., 2015). Receptors binding to S100A8 are known as both TLR4 and RAGE. In particular, TLR4 functions as an essential receptor in S100A8-induced inflammation (Pruenster et al., 2015).

$\mathrm{T}$ Lymphocytes regulate both innate and adaptive immune responses by secreting a variety of cytokines, including IL-6,

* Received: June 22, 2016 / Accepted: June 29, 2016

${ }^{\dagger}$ Corresponding author: In Sik Kim. Department of Biomedical Laboratory Science School of Medicine, Eulji University 77 , Gyeryoung-ro 771 beon-gil, Jung-Gu, Daejeon 34824, Korea.

Tel: +82-42-259-1753, Fax: +82-42-259-1759, e-mail: orientree@eulji.ac.kr

${ }^{\dagger}$ Corresponding author: Seung-Ju Yang. Department of Biomedical Laboratory Science, Konyang University 158, Gwangeodong-ro, Seo-gu, Daejeon 35365, Korea.

Tel: +82-42-600-6372, Fax: +82-42-600-6379, e-mail: sjyang@konyang.ac.kr

(C) The Korean Society for Biomedical Laboratory Sciences. All rights reserved.

(c) This is an Open Access article distributed under the terms of the Creative Commons Attribution Non-Commercial License (http://creativecommons.org/licenses/by-nc/3.0/) which permits unrestricted non-commercial use, distribution, and reproduction in any medium, provided the original work is properly cited. 
IL-8/CXCL8, and MCP-1/CCL2 (Tsai et al., 2011; Kang et al., 2014; Kim et al., 2015). Overexpression of these cytokines induces excess migration, proliferation, and differentiation, resulting in inflammation (Kang et al., 2015). We have recently reported that the house dust mite increases expression of IL-6, IL-8, and MCP-1 in normal and allergic lymphocytes, which results in inhibition of neutrophil apoptosis (Lee et al., 2016).

\section{MATERIALS AND METHODS}

\section{Reagents}

RPMI 1640 and fetal bovine serum (FBS) were purchased from Life Technologies Inc. (Gaithersburg, MD). CLI-095, an inhibitor of Toll-like receptor (TLR) 4 (TLR4i), was purchased from Invivogen (San Diego, CA, USA). PI3K inhibitor (Ly294002), PKCס inhibitor (rottlerin), MEK inhibitor (PD98059), p38 MAPK inhibitor (SB202190), JNK inhibitor (SP600125), and NF- $\mathrm{BB}$ inhibitor (BAY-11-7085) were purchased from Calbiochem (San Diego, CA, USA). Antibodies against phospho-ERK1/2, phospho-p38 MAPK,

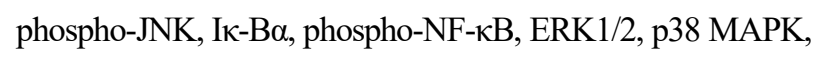
JNK, NF- $\kappa$ B, $\beta$-actin were purchased from Santa Cruz Biotechnology (Santa Cruz, CA, USA).

\section{Cell culture}

Jurkat $\mathrm{T}$ cells were obtained from the American Type Culture Collection (Manassas, VA, USA) and were maintained in RPMI 1640 medium with 10\% heat-inactivated fetal bovine serum (FBS), penicillin $(100 \mathrm{U} / \mathrm{ml})$, and strepto-
A
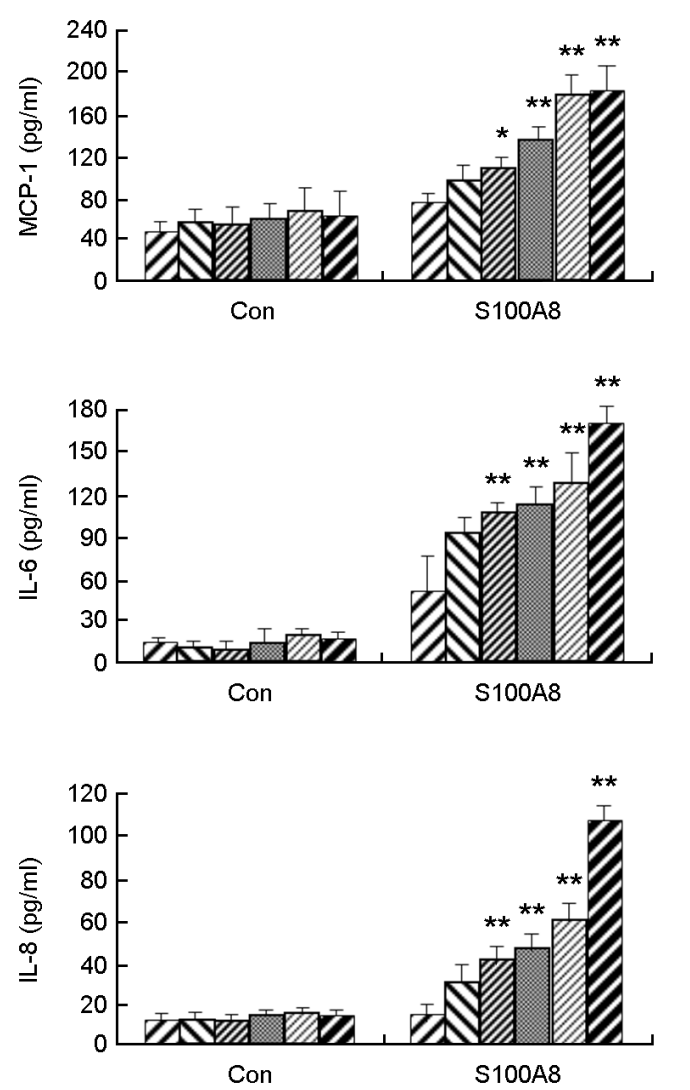

B
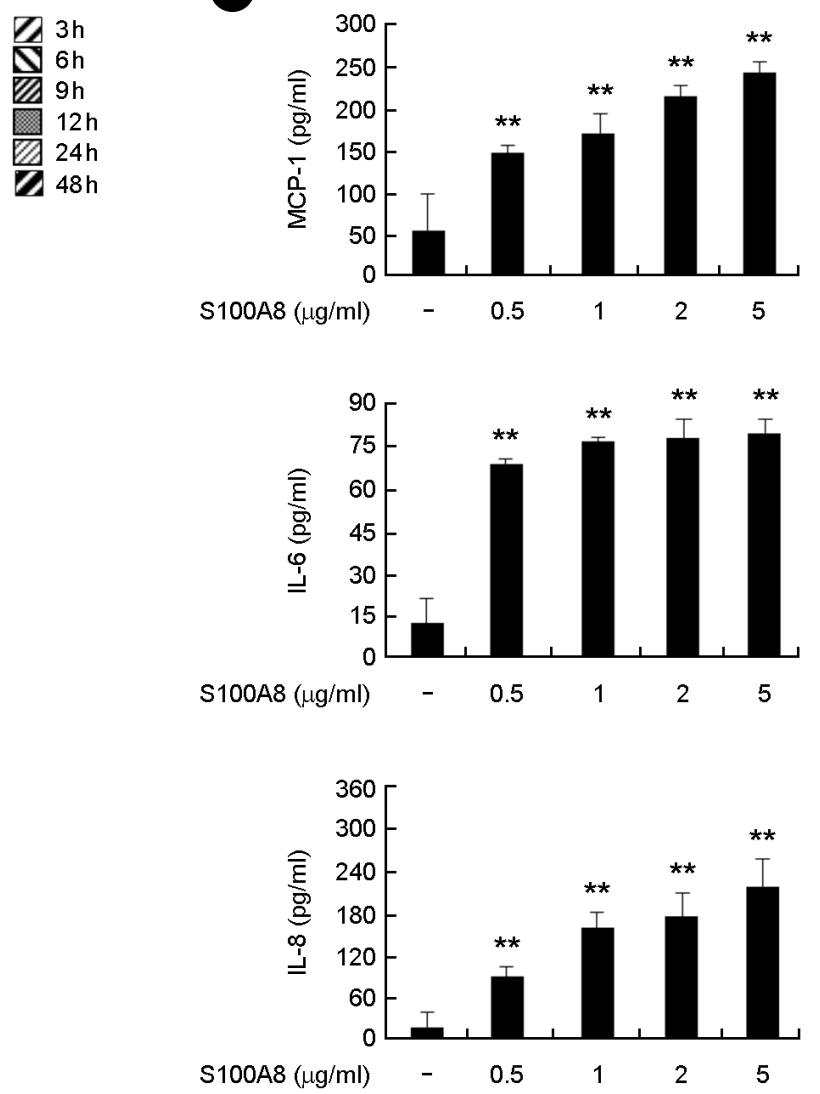

Fig. 1. DP induces the secretion of MCP-1, IL-6, and IL-8 in Jurkat T cells. (A) Jurkat T cells were incubated in the absence or presence of $5 \mu \mathrm{g} / \mathrm{mL} \mathrm{S100A8}$ for the indicated time or (B) Jurkat T cells were incubated at the indicated concentrations of S100A8 for $48 \mathrm{~h}$. The supernatant was collected and analyzed by ELISA. ${ }^{*} P<0.05$ and ${ }^{* *} P<0.01$ indicate a significant difference between the control and S100A8-treated groups. 
$\operatorname{mycin}(100 \mu \mathrm{g} / \mathrm{ml})$.

\section{Enzyme-linked immunosorbent assay (ELISA)}

The concentrations of IL-6, IL-8, and MCP-1 in a cell supernatant were measured with a sandwich enzyme-linked immunosorbent assay (ELISA) using OptEIA ${ }^{\mathrm{TM}}$ Set human IL-6, IL-8, and MCP-1 (BD Biosciences, San Diego, CA, USA) according to the manufacturer's instructions.

\section{Western blotting}

After being treated with arazyme, neutrophils were harvested and then lysed in $50 \mu \mathrm{L}$ lysis buffer (20 mM HEPES, $400 \mathrm{mM} \mathrm{NaCl}, 1 \mathrm{mM}$ EDTA, 1 mM EGTA, 25\% glycerol, $1 \mathrm{mM}$ dithiothreitol, $0.1 \mathrm{mM} \mathrm{Na} \mathrm{VO}_{4}$, and protease inhibitors). They were centrifuged at $12,000 \mathrm{~g}$ for $15 \mathrm{~min}$ at $4{ }^{\circ} \mathrm{C}$. The protein samples $(50 \mu \mathrm{g} / \mathrm{lane})$ were separated by $10 \%$ sodium dodecyl sulfate-polyacrylamide gel electrophoresis and the proteins were transferred to nitrocellulose filters. The blots were incubated with primary and secondary antibodies, and then developed using the enhanced chemiluminescence detection system (Amersham Pharmacia Biotech).

\section{NF-кB p65 transcription factor assay}

The DNA-binding activity of NF- $\kappa \mathrm{B}$ was assessed using EZ-Detect ${ }^{\mathrm{TM}}$ transcription factor kits for NF- $\kappa \mathrm{B}$ p65 (Pierce, Rockford, IL) according to the manufacturer's instructions. DNA binding specificity was assessed using wild type or mutant NF- $\mathrm{BB}$ oligonucleotides. Chemiluminescent detection was performed using a luminometer.

\section{Statistical analysis}

Data were expressed as the means \pm SD. Statistical differences were analyzed using a paired $t$-test for two-group comparisons and one-way ANOVA for comparison of more than two groups. All analyses were conducted using the SPSS statistical software package (Version 10.0, Chicago, IL), and a $P$ value $<0.05$ was considered to indicate statistical significance.

\section{RESULTS AND DISCUSSION}

\section{S100A8 increases secretion of MCP-1, IL-6, and IL-8 in} Jurkat T lymphocytes

In this study, we used Jurkat cells as an in vitro model for investigating the effect of S100A8 on cytokine release in T lymphocytes. As shown in Fig. 1, S100A8 significantly increased production of MCP-1, IL-6, and IL-8 in a time and dose-dependent manner $(P<0.05)$. Both MCP-1 and IL-8 trigger inflammatory responses by inducing migration, activation, and survival of monocytes and neutrophils (Kim
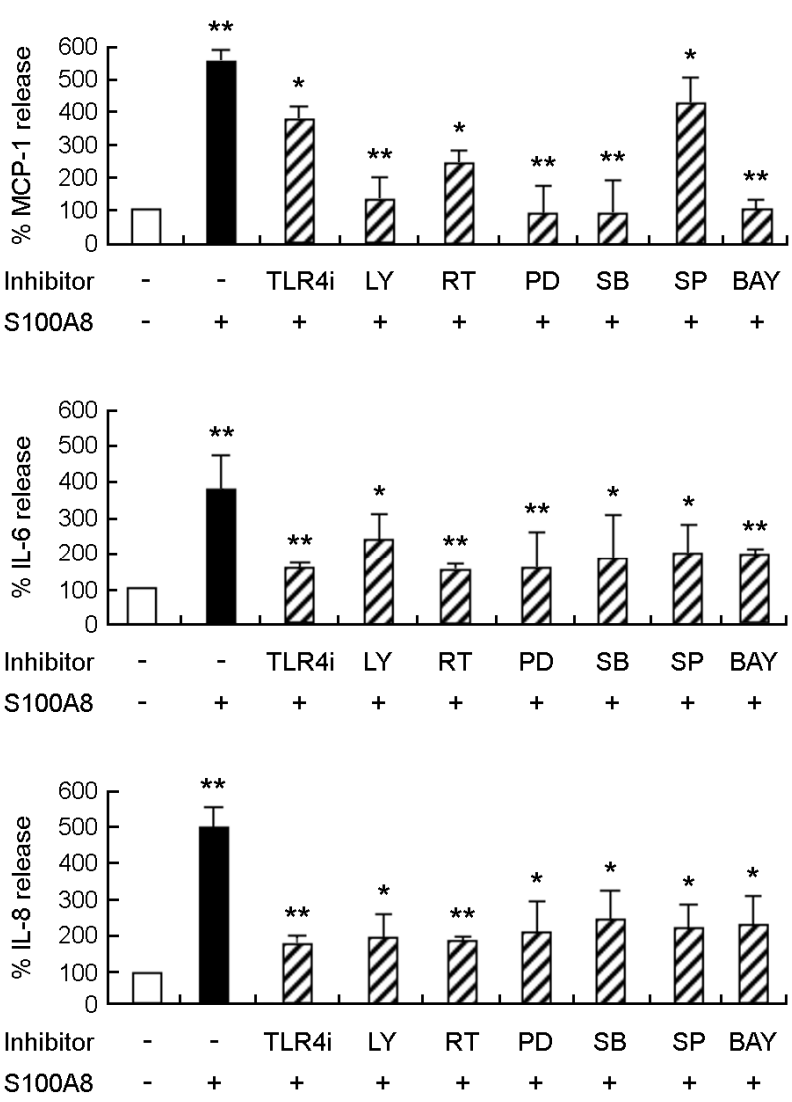

Fig. 2. Cytokine secretion due to $\mathrm{S100A8}$ is associated with TLR4, PI3K, PKCס, MAPKs, NF-KB. Jurkat T cells were pretreated for $1 \mathrm{~h}$ with and without TLR4i, and $10 \mu \mathrm{M} \mathrm{Ly} 294002$ (LY), $5 \mu \mathrm{M}$ rottlerin (RT), $10 \mu \mathrm{M}$ PD98059 (PD), $10 \mu \mathrm{M}$ SB202190 (SB), $10 \mu \mathrm{M}$ SP600125 (SP), and $10 \mu \mathrm{M}$ BAY-11-7085 (BAY), after which the cells were incubated for $48 \mathrm{~h}$ in the absence and presence of S100A8 $(5 \mu \mathrm{g} / \mathrm{mL})$. The supernatant was collected and analyzed by ELISA. $* P<0.05$ and $* * P<0.01$ indicate a significant difference between the control and S100A8-treated groups or between the S100A8-treated and the inhibitor-treated groups. 
(A)

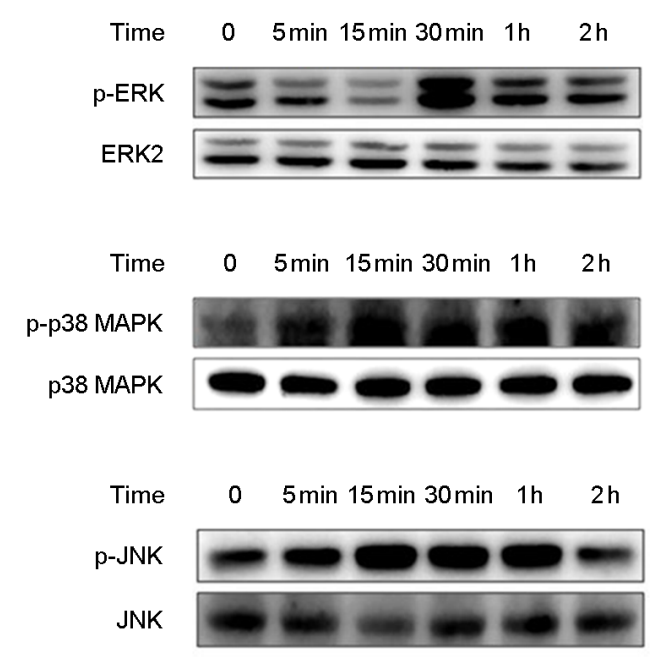

C

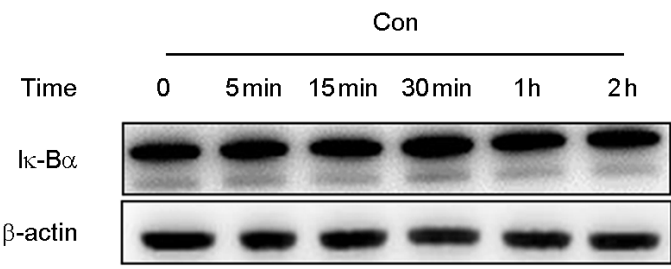

(D)

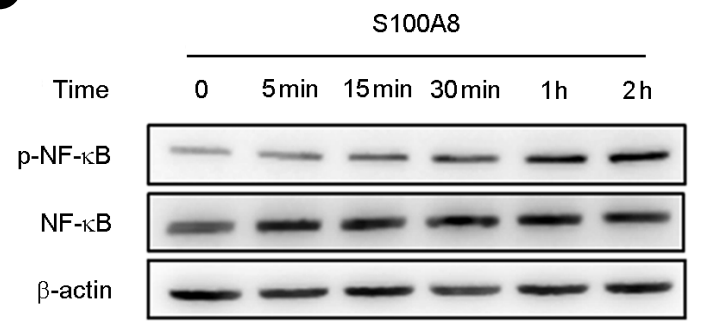

B

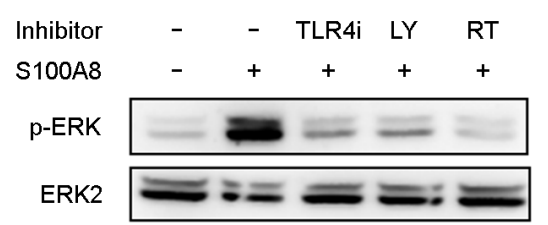

Inhibitor - $\quad-$ TLR4i LY RT

S100A8 - $+\quad+\quad+\quad+$
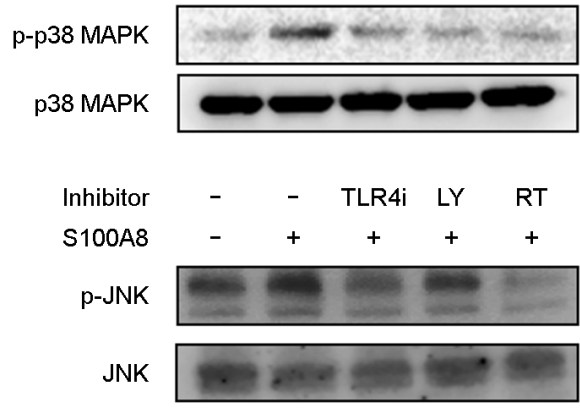

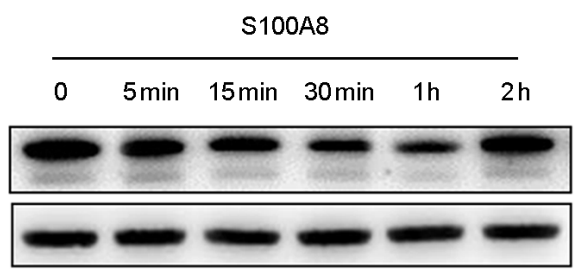

E

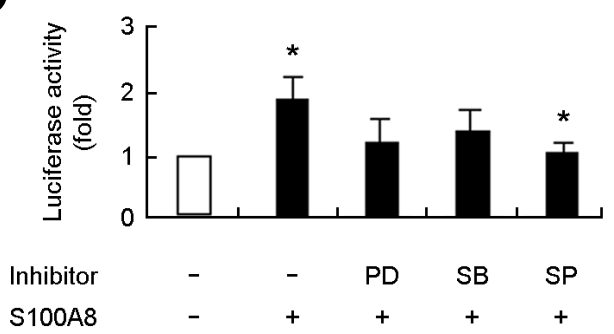

Fig. 3. S100A8 induces MAPKs and NF-kB activation via TLR4, PI3K, PKC $\delta$ in Jurkat T cells. (A) Jurkat T cells were incubated with S100A8 $(5 \mu \mathrm{g} / \mathrm{mL})$ for the indicated time. (B) Jurkat T cells were pre-treated for $1 \mathrm{~h}$ with and without TLR4i, $10 \mu \mathrm{M}$ Ly294002 (LY), and $5 \mu \mathrm{M}$ rottlerin, after which the cells were incubated for $30 \mathrm{~min}$ in the absence and presence of S100A8 $(5 \mu \mathrm{g} / \mathrm{mL})$. The harvested cells were lysed and phosphorylation of ERK, p38 MAPK, and JNK in the lysates was detected by Western blotting. (C and D) Jurkat T cells were incubated with S100A8 $(5 \mu \mathrm{g} / \mathrm{mL})$ for the indicated time after which harvested cells were lysed, and expression of Iк-B $\alpha$ and phosphorylation of NF- $\kappa \mathrm{B}$ in the lysates was detected by Western blotting. (E) Jurkat T cells were pre-treated for $1 \mathrm{~h}$ with and without $10 \mu \mathrm{M}$ PD98059 (PD), $10 \mu \mathrm{M}$ SB202190 (SB), and $10 \mu \mathrm{M}$ SP600125 (SP), after which the cells were incubated for $2 \mathrm{~h}$ in the absence and presence of S100A8 (5 $\mu \mathrm{g}$ $\mathrm{mL}$ ). After harvested cells were lysed, NF- $\mathrm{kB}$ in the lysates was detected by luciferase assay. Data are presented relative to the control, which was set at $100 \% . * P<0.05$ indicates a significant difference between the control and S100A8-treated groups or the S100A8-treated and inhibitor-treated groups.

et al., 2015). IL-6 is a pleiotropic cytokine, which is involved in inflammation after stimulation with an infectious antigen and allergen (van der Poll et al., 1997; Kim et al., 2014).
These results indicate that $\mathrm{S} 100 \mathrm{~A} 8$ is associated with the inflammatory response mediated by $\mathrm{T}$ cells. 


\section{DP induces release of MCP-1, IL-6, and IL-8 via acti-

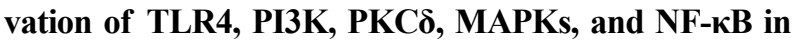 Jurkat $\mathrm{T}$ lymphocytes}

Since S100A8 induces cytokine secretion, we examined the associated signaling mechanism by using various signaling inhibitors. TLR4i, LY294002, rottlerin, PD98059, SB202190, SP600125, and BAY-11-7085 significantly suppressed secretion of MCP-1, IL-6, and IL-8 induced by S100A8 despite different degrees of inhibition $(P<0.05)$ (Fig. 2). These results show that the S100A8-mediated mechanism involves TLR4, PI3K, PKC $\delta$, MAPKs, and NF- $\mathrm{BB}$. As shown in Fig. 3A and B, S100A8 induced phosphorylation of ERK, p38 MAPK, and JNK, whereas activation was blocked by TLR4i, LY294002, and rotterlin, indicating that TLR4, PI3K, and PKC $\delta$ are upstream molecules of MAPK activation. S100A8 also activated NF- $\kappa B$ by $\mathrm{I} \kappa-\mathrm{B} \alpha$ degradation and $\mathrm{NF}-\kappa \mathrm{B}$ phosphorylation in a time-dependent manner (Fig. 3C and D). NF- $\kappa$ B activity due to S100A8 was inhibited by MAPKs such as PD98059, SB202190, and SP600125 (Fig. 3E). We previously reported that the house dust mite induces secretion of IL-6, IL-8, and MCP-1 via the PAR2/PI3K/Akt/ERK/NF- $\kappa$ B pathway in normal and allergic lymphocytes containing both $\mathrm{B}$ and T cells. This mechanism does not involve TLR4, although DP can activate TLR4 (Lee et al., 2016). However, this study shows that TLR4 is associated with cytokine expression due to S100A8 in Jurkat $\mathrm{T}$ cells. These differences may have various causes, including separation of $\mathrm{B}$ and $\mathrm{T}$ cells and the action of different stimulators. These findings shed new light on the complex mechanism induced by S100A8.

\section{Conflict of interest}

The authors have no financial conflicts of interest.

\section{REFERENCES}

Donato R, Cannon BR, Sorci G, Riuzzi F, Hsu K, Weber DJ, Geczy

CL. Functions of S100 proteins. Curr Mol Med. 2013. 13: 24 -57 .

Jin S, Park CO, Shin JU, Noh JY, Lee YS, Lee NR, Kim HR, Noh

S, Lee Y, Lee JH, Lee KH. DAMP molecules S100A9 and
S100A8 activated by IL-17A and house-dust mites are increased in atopic dermatitis. Exp Dermatol. 2014. 23: 938-941.

Kang BK, Kim MA, Park SH, Lee EJ, Kim JS, Kim EJ, Baek SY, Kim IS. The house dust mite allergen, Dermatophagoides pteronyssinus regulates the constitutive apoptosis and cytokine secretion of human eosinophils. Biomed Sci Lett. 2014. 20: $39-42$.

Kang JH, Hwang SM, Chung IY. S100A8, S100A9 and S100A12 activate airway epithelial cells to produce MUC5AC via extracellular signal-regulated kinase and nuclear factor- $\mathrm{B}$ pathways. Immunology. 2015. 144: 79-90.

Kim IS, Kim EH, Kim DH, Kim JS, Lee JS. Effect of house dust mite and CCL2 on S100A8 and S100A9 expression in human monocytes. Biomed Sci Lett. 2013. 19: 344-347.

Kim EH, Lee JS, Lee NR, Baek SY, Kim EJ, Lee SJ, Kim IS. Regulation of constitutive neutrophil apoptosis due to house dust mite all rgen in normal and allergic rhinitis subjects. PLoS One. 2014. 9: e105814.

Kim IS, Lee NR, Lee JS. Der p 1 inhibits spontaneous neutrophil apoptosis by cytokine secretion of normal and allergic lymphocytes. Korean J Clin Lab Sci. 2015. 47: 230-236.

Lee NR, Baek SY, Gu A, Kim DH, Kim SY, Lee JS, Kim IS. House dust mite allergen suppresses neutrophil apoptosis by cytokine release via PAR2 in normal and allergic lymphocytes. Immunol Res. 2016. 64: 123-132.

Pruenster M, Kurz AR, Chung KJ, Cao-Ehlker X, Bieber S, Nussbaum CF, Bierschenk S, Eggersmann TK, Rohwedder I, Heinig K, Immler R, Moser M, Koedel U, Gran S, McEver RP, Vestweber D, Verschoor A, Leanderson T, Chavakis T, Roth J, Vogl T, Sperandio M. Extracellular MRP8/14 is a regulator of $\beta 2$ integrin-dependent neutrophil slow rolling and adhesion. Nat Commun. 2015. 6: 6915.

Tsai JJ, Liu SH, Yin SC, Yang CN, Hsu HS, Chen WB, Liao EC, Lee WJ, Pan HC, Sheu ML. Mite allergen Der-p2 triggers human B lymphocyte activation and Toll-like receptor-4 induction. PLoS One. 2011. 6: e23249.

van der Poll T, Keogh CV, Guirao X, Buurman WA, Kopf M, Lowry SF. Interleukin-6 gene-deficient mice show impaired defense against pneumococcal pneumonia. J Infect Dis. 1997. 176: 439-444.

Zheng R, Chen S, Chen, S. Correlation between myeloid-derived suppressor cells and S100A8/A9 in tumor and autoimmune diseases. Int Immunopharmacol. 2015. 29: 919-925. 